\title{
SEGURANÇA PARA QUEM? UNIDADE DE POLÍCIA PACIFICADORA E GESTÃO DA POBREZA
}

\author{
Security for whom? The Pacifying Police Unit and the poverty \\ management
}

\section{Alejandra Pastorini}

Professora Associada da Escola de Serviço Social da UFRJ

\section{Ana Carolina Perdigão}

Assistente Social do Hospital Federal de Ipanema

\section{Aparecida Tavares da Silva}

Discente da ESS/UFRJ

\section{Sara Izabeliza Moreira Lima}

Assistente Social Residente no Instituto Nacional de Câncer: José de Alencar Gomes Silva.

\section{Resumo}

O presente trabalho tem como preocupação central analisar a lógica que orienta as intervenções do poder público, no Rio de Janeiro, direcionadas para as populações mais empobrecidas, tomando como exemplo o programa Unidade de Polícia Pacificadora (UPP) que começou a ser implementado nesta cidade em 2008. Entretanto, nossa pesquisa vem indicando que este Programa, por um lado, reforça o processo de criminalização da pobreza e contribui para consolidar as ações coercitivas e punitivas do Estado (ocupações militarizadas, uso da violência etc.) e, por outro, contribui para criar as condições necessárias para o processo de acumulação do capital (consolidando novos nichos de valorização como especulação imobiliária, ampliação do fundo público pelo setor privado etc.).

Palavras-chave: Questão social. Estado. Políticas Públicas. Segurança Pública. Pobreza

\begin{abstract}
This paper has the central concern of analyzing the logic that guides the interventions of public power in Rio de Janeiro, directed to the most impoverished population, taking as an example the program Pacifying Police Unit (UPP) that started to be implemented in this city in 2008. However, our research has shown that this program, on the one hand, reinforces the process of criminalization of poverty and contributes to the consolidation of the coercive and punitive actions of the State (military occupations, use of violence, etc.) and, on the other hand, contributes to create the necessary conditions for the capital accumulation process (consolidating new valuation niches like real estate speculation, expansion of the public fund by the private sector, etc.).
\end{abstract}

Keywords: Social question; State; public policies; public security; poverty

\section{Sumário}

1. Introdução; 2. As transformações na organização do capital e as particularides do Brasil na contemporaneidade; 3 . Lógica que fundamenta as Unidades de Polícia Pacificadora; 4. As particularidades do programa de UPP no Rio de Janeiro; 5. Considerações finais; 6 . Notas; Referências. 


\section{INTRODUÇÃO}

Este trabalho busca problematizar a lógica que orienta a prática do programa de Unidade de Polícia Pacificadora (UPP), executado na cidade do Rio de Janeiro desde 2008 quando se instalou a primeira UPP no Morro Santa Marta. Estas reflexões são produto da pesquisa que desenvolvemos entre os anos 2013-2016, que tinha como objetivo analisar os fundamentos que orientavam as intervenções do poder público nessa cidade e direcionadas para os setores mais pauperizados. Nessa investigação, foi possível identificar íntima relação entre as ações assistenciais focalizadas nos setores vítimas da pobreza absoluta e as estratégias de controle e repressão. Mesmo não sendo uma novidade que as manifestações da questão social no Brasil sejam tratadas através de práticas punitivas e repressivas por parte do poder público, entendemos que essa estratégia assume um novo caráter com a implantação do programa UPP.

Nossas reflexões tomaram como referência dois pressupostos centrais. O primeiro deles se vincula à idéia de que para entender as alterações produzidas pelas intervenções do poder público na administração das manifestações da questão social, é necessário desvendar as transformações na organização do capital a partir dos anos 1970, uma vez que essa nova realidade vai exigir importantes mudanças na estrutura e funções do Estado, redesenhando o formato das políticas públicas. Esse conjunto de transformações vai alterar a relação entre público e privado, como forma de criar as condições para a acumulação do capital, contribuindo com a consolidação de novos nichos de valorização.

Nesse contexto, o espaço e a produção da cidade "transforma-se em objeto das estratégias que visam impulsionar a acumulação de capital, (...) o que amplia o campo de tensões e conflitos, pois o que se encontra em questão é assegurar a produção e a reprodução das relações sociais de produção essenciais ao capitalismo através da produção do espaço" (Coutinho, 2013. online). Neste sentido, analisar as intervenções do poder público para atender as manifestações imediatas da questão social, como, por exemplo, a pobreza, desemprego, violência etc., só será possível sempre que vinculadas à lógica que estrutura a organização capitalista, que determina as particularidades dos processos de urbanização da pobreza, hoje, cada vez mais, através da combinação entre ações assistenciais, controladoras e coercitivas.

O segundo pressuposto que guia nossas reflexões vincula-se à idéia de que os Mega Eventos como Copa do Mundo de Futebol FIFA e os Jogos Olímpicos são utilizados como estratégias fundamentais para ampliar os espaços de investimento do capital superacumulado, uma vez que a realização desses eventos esportivos coloca como exigência por parte dos seus organizadores um intenso processo de transformações e adequação das cidades sedes; a criação do programa de UPP pode ser considerado como um exemplo.

Assim, organizamos este artigo em três sessões e as considerações finais. Começamos analisando as transformações na organização do capital, a partir dos anos 1970, e as novas requisições postas para o Estado, focando nossa atenção nas estratégias de atendimento das manifestações da questão social. A segunda parte trata dos fundamentos políticos e ideológicos do Programa de Unidade de Polícia Pacificadora e as possíveis rela- 
ções deste Programa com a estratégia de "tolerância zero". Já a terceira sessão aprofunda as reflexões acerca das UPPs, enquanto estratégia de administração da pobreza no Rio de Janeiro e instrumento fundamental para criar as condições necessárias para valorizar o capital. Fechamos estas reflexões com as considerações finais que buscam sintetizar o percurso analítico.

\section{AS TRANSFORMAÇÕES NA ORGANIZAÇÃO DO CAPITAL E AS PARTICULARIDES DO BRASIL NA CONTEMPORANEIDADE}

Até os anos 1970, os monopólios organizados com base no capital industrial e bancário, conseguiram atingir importantes taxas de valorização apoiados no binômio crescimento econômico e redistribuição de renda. Essa equação perdurou por quase trinta anos a partir da Segunda Guerra Mundial, até o momento que se torna explosiva a crise do capital, que deixa em evidência o esgotamento do padrão de acumulação fordista-taylorista.

A partir de então, se consolida um novo padrão de acumulação, conhecido como flexível - em oposição à rigidez do fordismo -, apoiado em uma nova organização da produção que foi facilitada pelas transformações tecnológicas e científicas que permitem desenvolver, também, novas formas de controlar o trabalho e de intensificar a exploração do trabalhador. Essas mudanças na esfera da produção, que passam a ser conhecidas como reestruturação produtiva, contribuíram, ao mesmo tempo, com a fragilização da organização e da luta da classe trabalhadora.

A nova realidade que se consolida, a partir de então, no mundo capitalista em seu conjunto, impõe a necessidade de encontrar novas formas e espaços para valorizar o capital superacumulado. A indústria bélica e a divisão internacional do trabalho, juntamente com a produção de produtos descartáveis continuam a ser importantes estratégias para acelerar a rotação do capital. A essa situação, agrega-se a necessidade de aprimorar os mecanismos para controlar o trabalho e a superpopulação relativa, num quadro em que a população sobrante aumenta de forma significativa devido às mudanças na composição orgânica do capital e às próprias particularidades do processo de valorização, num contexto em que o processo de acumulação encontra-se comandado pelos grandes grupos industriais transnacionais articulados de forma íntima ao mundo das finanças (bancos, agências de seguros etc.

A partir desse momento, a compra de títulos das dívidas públicas dos países localizados na periferia do capitalismo e a exportação de capitais também passam a ser mecanismos centrais para consolidar os novos nichos de valorização. Assim, os processos de privatização direta e indireta das empresas e serviços públicos somam-se às estratégias de acumulação comandadas pelo capital financeiro.

Esse conjunto de transformações, que implicam em uma reorganização do capital, contribui para aumentar a expulsão de trabalhadores do processo de produção. Tal como indica Marx (1982), a existência da superpopulação relativa é uma problemática peculiar ao modo de produção capitalista, uma vez que "a força de trabalho tem de incorporar-se con- 
tinuamente ao capital, como meio para expandi-lo [...] e sua, reprodução constitui, na realidade, um fator de reprodução do próprio capital" (p.714). Ou seja, a população excedente é um produto da acumulação e, ao mesmo tempo, condição necessária para a valorização do capital.

Foi assim que, durante um longo período do capitalismo monopolista, as políticas sociais assumiram uma função central contribuindo com a produção e reprodução da força de trabalho ocupada e excedente. Mas, na atualidade a população supérflua assume dimensões que não podem ser comparadas com os períodos anteriores. É perceptível que o desemprego é na atualidade um problema crônico, e se torna mais grave devido ao agravo exponencial das condições de vida e de trabalho dos trabalhadores em seu conjunto. A precarização impregna a totalidade do processo de produção e de reprodução dos sujeitos produtores da riqueza social.

A precarização do trabalho é uma expressão da superexploração dos trabalhadores, que se concretiza na nova fase de mundialização financeira do capital através da flexibilização dos contratos de trabalho, das legislações trabalhistas e dos direitos sociais, e das organizações dos trabalhadores como, por exemplo, os sindicatos. É notório o aprofundamento do desemprego, a prevalência de vínculos de trabalhos temporários, o aumento do processo de terceirização, o duplo emprego ou pluriemprego, que são uma afronta direta aos direitos conquistados ao longo dos anos, e uma estratégia utilizada pelo capital para massificação da taxa de lucro, devido à incerteza e a vulnerabilidade dos trabalhadores que só possuem sua força de trabalho para vender (ANTUNES, 2007).

Dessa forma, podemos afirmar que o aumento do desemprego e a intensificação da precarização são produtos e condições das novas formas de se organizar o capital para enfrentar a crise que explodiu nos anos 1970. Perante essa nova realidade, as estratégias utilizadas pelo Estado para atender as manifestações da questão social, que tinham como pilar às políticas sociais, são colocadas em questão pelas classes dominantes, na medida em que não se sintonizam com as novas necessidades da acumulação. Nesse contexto de transformações estruturais, se produzem inúmeros diagnósticos, relatórios, estudos e pesquisas fundamentadas no ideário neoliberal e conservador que justificam a necessidade de reformar o Estado (tanto sua estrutura quanto suas funções).

Na Europa ocidental, onde existiram as experiências de Welfare State, o Estado passa a ser responsabilizado pela crise (reduzida a uma crise fiscal e política); já nos países dependentes localizados na periferia, que não vivenciaram as experiências dos Estados de bem-estar social, os principais alvos de crítica passam a ser as empresas públicas, as formas tradicionais de explorar/conservar as riquezas naturais e os mecanismos de proteção social que foram estruturados inícios do século $X X$.

A partir desse momento, amplia-se a preocupação em ocupar os espaços e regiões não capitalizadas. Também a exportação de capitais superacumulados se torna uma estratégia fundamental para manter a valorização. A este respeito Harvey (2004) dirá que se amplia a acumulação por espoliação, definida pelo autor como um processo em que os excedentes de capital ociosos que não encontram espaço para serem valorizados nos países impe- 
rialistas, descobrem nos países periféricos um conjunto de ativos (terra, força de trabalho, riquezas naturais etc.), a um preço muito baixo, constituindo-se em nichos fundamentais para valorização.

Essa realidade requer um Estado que regule de outra forma, contribuindo com: a flexibilização das legislações, a mobilidade do capital, o livre acesso às matérias primas, riquezas naturais e força de trabalho. Este processo de espoliação, tratado por Harvey (idem.), combina-se com a pilhagem, fraude, violência e destruição da força de trabalho e da natureza.

As classes dominantes, recorrendo às elaborações de Hayek, defendem a redução da intervenção do Estado, principalmente com relação à proteção e à garantia dos direitos sociais, trabalhistas e políticos dos trabalhadores. Dessa forma, vários autores entenderão que se trata de consolidar um "Estado mínimo". Mas, como indica Anderson (1995), esse Estado deverá ser forte para conter a organização dos trabalhadores e se contrapor à sua luta. Também, essa nova realidade coloca a necessidade de reestruturar os mecanismos existentes para gerir a superpopulação relativa, reforçando os aspectos coercitivos.

Quando nos aproximamos da realidade brasileira, constatamos que essas mudanças começam a ser implantadas a partir da segunda metade dos anos 1990, quando inicia o processo denominado como contrarreforma do Estado - materializado através de alterações na gestão pública, nas funções do Estado e na sua máquina administrativa. A reformulação da proteção social brasileira é um elemento a ser destacado. Por um lado, existe o estímulo e incentivo por parte dos organismos financeiros multilaterais para que o Estado reduza seu papel de provedor direto dos serviços sociais - como, por exemplo, nas áreas da saúde, educação e previdência -; por outro lado, se robustece o caráter punitivo do poder público.

No primeiro caso, a estratégia de privatização direta e, principalmente, indireta, materializada através dos novos mecanismos de gestão, contribui de forma significativa para ampliar o acesso do setor privado ao fundo público de recursos que, em parte, se destinaria aos serviços sociais. Dessa forma, o Estado focaliza os programas sociais para os setores mais pauperizados através da organização das ações em redes mínimas de proteção. Já o endurecimento do caráter coercitivo do Estado vai se expressar de variadas formas: na intensificação da onda de criminalização da pobreza e dos movimentos sociais, na aposta no sistema carcerário como mecanismo de contenção do crime, nos investimentos em sistemas de controle e vigilância, no aumento do protagonismo e liberdade dos atores estatais responsáveis pela segurança, assim como, na aposta da dimensão controladora e moralizadora no interior dos programas assistenciais.

Todas essas transformações - e, em alguns casos, intensificação de estratégias do Estado - com uma clara orientação punitiva determinada pelo ideário neoliberal, se consolidam no Brasil, quando a pobreza absoluta e a miséria assumem centralidade na pauta dos governos dos países periféricos, em resposta às exigências dos organismos multilaterais preocupados com a garantia da governança e da estabilidade política.

É nesse contexto de transformações econômicas e políticas que vão sendo formulados vários programas, como é o caso das Unidades de Polícia Pacificadora, que com a 
pretensão de garantir a proteção e segurança dos cidadãos desenvolvem uma importante engenharia controladora e punitiva das populações mais empobrecidas.

Para Davis (2006), essa estratégia não é uma completa novidade na região, uma vez que, desde os anos 1970-80, o Banco Mundial amplia os empréstimos para o setor de desenvolvimento urbano. Esse investimento é importante, por um lado, para incidir e dar direção aos programas vinculados à política urbana; e por outro, foi extremadamente útil para alimentar as ONGs e as empresas privadas que viabilizavam os programas e as obras de urbanização, contribuindo com a especulação imobiliária. Além da importância, enquanto espaços de valorização do capital superacumulado, estas estratégias contribuem para consolidar um conjunto de ideias e explicações acerca da pobreza, subdesenvolvimento, das necessidades, do crime etc. - que o Banco Mundial chamará mais tarde de Banco de Ideias - que serão fundamentais para justificar as políticas punitivas, a focalização na pobreza e as reformas em geral.

Vale mencionar que entre os anos 1980 e os anos 2000, os índices de violência e criminalidade no Brasil em geral e no Rio de Janeiro, em particular, cresceram rapidamente, assim como o número de mortes em conflitos armados. ${ }^{1}$ Mas é necessário levar em consideração mais um dado para pensar o Rio de Janeiro, como indica Burgos,

\footnotetext{
Nos anos 80, o problema da favela iria conhecer uma nova complexidade, com maior presença de grupos paraestatais no mundo dos excluídos: de um lado, os banqueiros do jogo do bicho, que embora presentes desde o início dos anos 70 na vida das favelas e conjuntos habitacionais, ganham maior evidência a partir dos anos 80 , de outro lado, grupos dedicados a o tráfico de entorpecentes (2003, p.43)
}

Essa realidade se vincula às particularidades do processo de favelização, ainda que pese algumas mudanças produzidas nos anos 1980, no governo de Brizola; esses espaços continuaram a ser caracterizados pela ausência de políticas sociais e pela presença da violência por parte do Estado.

Essa relação do Estado com as favelas foi alimentando um processo de criminalização das populações que as habitam, apoiado na suposta relação entre pobreza e crime, reforçando a ideia que esses setores por constituírem um perigo para a sociedade "integrada" precisam ser controlados, reprimidos e punidos. Dessa forma, vai se consolidando uma política de "segurança" para quem mora na favela e outra - articulada à primeira - para que mora fora dela, e/ou dela se utiliza. E essa ideia estigmatizante e discriminadora acerca da pobreza e da favela vai alimentar o conceito de que os setores empobrecidos são inimigos e representam um perigo para a sociedade. Ou seja, a infundada associação entre pobreza e delito ou entre favela e crime, amplamente difundida e defendida pela mídia, produz, na sociedade, o sentimento de medo e de insegurança, que justifica ações punitivas e repressivas, como, por exemplo, a militarização e que ainda, em alguns casos, serve de desculpa para as medidas arbitrárias por parte do poder público.

Como indica Morás, essas estratégias repressivas, coercitivas e punitivas colaboram com a "extensão das novas narrativas, atores e situações que promovem a insegurança e elabora uma cultura do medo como figura onipresente (...). [Dessa forma] o medo, a insegurança e a violência passaram a ser importantes fatores de coesão social” (2010, p.16). 
A cultura do medo serve como justificativa para intensificar as ações e práticas denominadas como segurança pública, mas que, na prática, constituem-se em verdadeiras estratégias de militarização do cotidiano dos setores mais pauperizados e de penalização/ punição de sujeitos e grupos específicos e não de atos ilícitos.

\section{LÓGICA QUE FUNDAMENTA AS UNIDADES DE POLÍCIA PACIFICADORA}

No ano 2007, assume o Governo do Estado do Rio de Janeiro, o ex-governador Sérgio Cabral que define dentre suas prioridades a reformulação da política de segurança pública no estado, propondo, dentre suas metas, a retomada do controle dos territórios perdidos pelo poder público, desde os anos 1980; o combate às facções criminosas e a devolução da paz e a segurança aos cidadãos.

Uma das estratégias centrais para atingir essas metas foi a criação do Programa de Unidade de Polícia Pacificadora (UPP), entendido por seus formuladores como uma peça fundamental do PRONASCI (Programa Nacional de Segurança Pública com Cidadania), ${ }^{2}$ aprovado em 2007, no segundo governo de Luiz Inácio Lula da Silva. Este Programa, guarda-chuva, que incluía mais de 90 ações em todo o território nacional, objetivava a prevenção e o enfrentamento da criminalidade, o controle e combate ao crime organizado, a qualificação e valorização dos profissionais envolvidos nesta área e a aproximação e articulação das políticas de segurança com as políticas sociais.

É assim que se propõe superar a lógica que orientava as políticas de segurança pública até aquele momento, porém sem ultrapassar de forma plena alguns elementos entendidos como gargalhos das políticas precedentes, como, por exemplo: a promoção dos direitos humanos, participação da sociedade civil e fortalecimento das redes comunitárias, a instalação da polícia de proximidade, a garantia de acesso à justiça a todos os cidadãos.

O PRONASCI propõe guiar as ações pelo denominado paradigma da segurança cidadã que incentiva as ações de prevenção, a participação da população e a aproximação dos cidadãos e da polícia no espaço local. Como menciona Freire (2009, p. 53), "as ações comunitárias ganham destaque nesse conceito e a construção de uma cultura cidadã na comunidade, incluindo o respeito às normas de convivência e a resolução pacífica de conflitos, é um dos pilares das ações de prevenção".

É importante mencionar que os defensores da Segurança Cidadã entendem que este paradigma supera o da Segurança $\mathrm{Nacional}^{3}$ que reinou no período da ditadura cívico-militar. Mas como analisa Freire (2009), esse paradigma, ao mesmo tempo que avança em relação àquele dominante entre os anos 1964-85, apresenta algumas tensões com a concepção de Segurança Pública presente na Constituição Federal de 1988.

Outros dados necessitam ser citados. O primeiro diz respeito a não desestruturação plena das instituições que foram o braço da Doutrina de Segurança Nacional (DSN) e a perpetuação da lógica que estruturou as ações de segurança pública ao longo dos vinte anos de ditadura cívico-militar. A presença, até hoje, do caráter militar da polícia voltada para a proteção da cidadania, é uma clara expressão dessa realidade; também a situação de vul- 
nerabilidade dos direitos humanos indica certa continuidade com a lógica da atuação militar baseada na "ficção de inimigos" da sociedade e da ordem. Nesse sentido, Salla indica que

\begin{abstract}
A impermeabilidade dessas esferas aos novos processos e demandas da sociedade democrática se revela, por exemplo, na dificuldade que o sistema político e os novos atores do cenário democrático enfrentam em reduzir os níveis de violência na atuação das forças policiais, sendo frequentes ainda os casos de civis mortos em confrontos com elas; na mesma direção, tem sido difícil acabar com a prática da tortura e da imposição de maus tratos nos ambientes prisionais; igualmente desafiador é reduzir os níveis de corrupção dentro da polícia e do sistema penitenciário... (2003, p.420)
\end{abstract}

O segundo elemento a ser mencionado se relaciona às particularidades das experiências na área de segurança pública orientadas pelo paradigma de segurança cidadã. Este modelo de segurança pública, a partir da década 1990, é tomado como referência em diversas experiências, como, por exemplo, em Nova York, Cali e Medellín, para mencionar os ensaios pioneiros e mais conhecidos. Em todas essas experiências a política de "tolerância zero" impregna as ações desenvolvidas na segurança pública, se combinando de forma tensa com os avanços trazidos pelo paradigma da Segurança Cidadã. A política de "tolerância zero" tomando como ponto de partida a ideia da insegurança causada pela criminalidade nas ruas, pelos bairros mais empobrecidos e pela delinquência (atribuída aos moradores de rua, imigrantes e mendigos) busca reduzir, ao máximo possível, a tolerância ao delito, sem se preocupar com a gravidade e consequências que o mesmo possa causar. Entende-se que essas populações (geralmente empobrecidas) atentam contra a ordem pública e se constituem em uma ameaça à segurança nacional; dessa forma, as respostas devem ser rápidas e os sujeitos protagonistas das ações duramente punidos.

Embora o Programa de UPP tenha sido criado no seio desse Programa Federal e orientado pela busca da "construção de uma cultura cidadã na comunidade", os dados da realidade nos indicam que essa experiência está muito distante da busca da "resolução pacífica de conflitos" e "das ações de prevenção". É possível perceber, por exemplo, a partir das constantes denúncias de moradores das favelas, que esta experiência carrega no seu interior uma contradição fundante entre o discurso de segurança cidadã e uma prática guiada pela reprodução da violência, estigmatização e criminalização da pobreza. Nos espaços das favelas, onde as UPP geralmente são instaladas, predominam ações como: invasão e controle de territórios, imposição das ações da polícia militar, toque de recolher, revista da população, abuso de autoridade etc. ${ }^{4}$

O Programa de Unidade de Polícia Pacificadora inicia, em 2008, com a ocupação por parte da Polícia Militar do Morro Santa Marta, experiência-piloto que foi considerada pela polícia militar e pela Secretaria de Estado de Segurança Pública do Rio de Janeiro bem-sucedida. Dessa forma, se coloca em andamento o processo denominado de "pacificação" das favelas do Rio de Janeiro, ${ }^{5}$ que se encontra em curso até a presente data.

Aqui entendemos que não é uma mera coincidência a escolha, em 2006/2007, do Brasil como sede da Copa do Mundo de Futebol de 2014 e, em 2009, a definição do Rio de Janeiro como sede dos Jogos Olímpicos de 2016. A realização desses grandes eventos esportivos está condicionada à adequação das cidades-sede às exigências dos seus organizadores (a FIFA e o COI - Comitê Olímpico Internacional) e dos grupos empresariais, em- 
preiteiras e especuladores em geral, que se utilizam dos megaeventos como oportunidade para criar novos espaços de investimento e oportunidades para a realização de negócios.

Concomitantemente à criação das Unidades de Polícia Pacificadoras na cidade do Rio de Janeiro começa a ser alargada a estratégia punitiva e de controle do poder público, sintonizado com as operações policiais tradicionais. A "guerra ao mundo das drogas" através do combate ao tráfico articula-se com os programas e ações que têm como objetivo a internação compulsória dos dependentes químicos, abordagem da população em situação de rua, Operação de Choque de Ordem - da Secretaria Especial da Ordem Pública do Rio de Janeiro (SEOP) - para combater a "desordem urbana", dentre outros. Este tipo de intervenções busca o controle e enfrentamento da violência que, segundo o discurso oficial, decorreria da vinculação entre essas situações de vulnerabilidade, o mundo das drogas e o crime organizado.

Na cidade do Rio de Janeiro, no contexto da realização dos megaeventos, há vários exemplos na área de transporte, urbanização e segurança pública que indicam como a transformação de esse espaço urbano é uma estratégia fundamental para impulsionar a acumulação e valorização do capital, dentre eles podemos mencionar: a extensão das linhas do metrô, reforma do Maracanã e seu entorno, o projeto Porto Rio Maravilha e da região portuária, o corredor de transporte BRT TransCarioca e TransOeste, a Construção da Vila Olímpica e as reformas dos Aeroportos. Nesse sentido, as reflexões de Coutinho $(2013$, p.5) são esclarecedoras quando destaca que "em todos os momentos da reprodução do capital, a interferência do Estado é fundamental e a sua ação desencadeia um processo de revalorização/desvalorização das áreas das cidades e, com isso, a expulsão/atração dos habitantes". Em muitos casos, os exemplos de "modernização" urbana mencionados acima, vieram acompanhados de remoções e despejo dos moradores das áreas a serem utilizadas pelas obras de remodelação e pelas novas construções realizadas na cidade; entendemos que nesse processo a implantação e ampliação das UPP foi uma estratégia fundamental.

\section{AS PARTICULARIDADES DO PROGRAMA DE UPP NO RIO DE JANEIRO}

O Programa de Unidade de Polícia Pacificadora começa a ser implantado no Rio de Janeiro no ano de 2008, com a experiência-piloto do Morro Santa Marta. Entretanto foi através do Decreto $n^{\circ}$. 41.650, de 21 de janeiro de 2009, que se ampliou o programa pela cidade do Rio de Janeiro. Este decreto define de forma clara os objetivos do Programa, as etapas de implantação e as reponsabilidades das diferentes esferas de governo.

De acordo com os documentos oficiais, o Programa da UPP tem a finalidade de retomar os territórios dominados por grupos criminosos, ostensivamente armados (BRASIL, 2009), essa retomada dar-se-ia através da materialização de quatro etapas que podem ser resumidas da seguinte forma: a) intervenção tática que consiste na invasão dos territórios por parte da Polícia Militar (MP), do Batalhão de Operações Policiais Especiais (BOPE) e das Forças Armadas, com o objetivo de retomar o comando da favela por parte do poder público; b) estabilização - implica no isolamento do território invadido (controlando a entrada, saída e circulação de pessoas) como forma de facilitar a ocupação do território por parte 
da Polícia Militar que é a responsável pela UPP; c) implantação da UPP busca ampliar a presença da polícia de proximidade na favela e criar as condições para a instalação e alargamento dos serviços públicos e privados nas favelas e d) avaliação e monitoramento, etapa final que consiste no acompanhamento das políticas e programas sociais fundamental para o aprimoramento do programa.

Até a presente data foram instaladas na cidade do Rio de Janeiro 38 UPPs, mas nos quase 10 anos de existência do Programa, o mesmo não tem ultrapassado a segunda etapa em nenhuma das favelas, ou seja, houve a ocupação e isolamento dos territórios invadidos e a presença da Política Militar administrando o cotidiano dos moradores. Entretanto, a polícia de proximidade e a instalação e melhoria dos serviços públicos são quase inexistentes nessas favelas.

Em algumas localidades, como, por exemplo, no morro Santa Marta, onde aconteceu a instalação da primeira UPP, é possível perceber o aumento da quantidade de serviços privados como telefonia, internet, TV por assinatura, agências de bancos, lojas comerciais, dentre outros. Entretanto, é visível a ausência de serviços públicos básicos como: equipamentos de saúde, de educação, na área da cultura e lazer.

Esse dado é importante e, mais ainda, se considerarmos que, segundo informações ministradas no site oficial do Programa, o mesmo se apoia nas parcerias entre o Estado (os governos municipal, estadual e federal) e empresas privadas (dentre elas: Grupo EBX, Bradesco Seguros, Light, Souza Cruz, Confederação Brasileira de Futebol).

Foi a partir dessas informações que buscamos focar nossa atenção no processo de instalação das UPPs nas diversas favelas "pacificadas" no Rio de Janeiro, buscando identificar o critério utilizado para a escolha das favelas invadidas. Assim classificamos as Unidade de Polícia Pacificadora em cinco grandes grupos:

No primeiro grupo encontram-se as UPPs localizadas no Jacarezinho, Manguinhos, Barreira do Vasco e Tuiuti, Caju, Arara e Mandela, Batan, Vila Kennedy e Complexo da Mangueirinha, todas elas situadas ao longo das principais vias de comunicação e acesso à cidade do Rio de Janeiro, como: aeroportos; vias expressas como, por exemplo, Avenida Brasil, Linha Amarela e Linha Vermelha e a região portuária. A implantação das UPPs, nessas comunidades, foi central para facilitar a entrada/saída da cidade, a mobilidade no seu interior e o acesso com segurança às regiões turísticas e de realização dos grandes eventos esportivos (Copa do Mundo e Jogos Olímpicos).

O segundo grupo reúne as UPPs localizadas na Providência, Coroa Fallet e Fogueteiro, São Carlos, ou seja, aquelas implantadas na região portuária e seu entorno; a ocupação desse território garante a segurança na região revitalizada, incentivando os investimentos das grandes empreiteiras como Odebrecth, Camargo Corrêa, Mendes Junior, Carioca Engenharia e OAS - empresas que têm protagonismo nas obras do Porto Maravilha, Estádio Olímpico João Havelange, o Engenhão e vias expressas como BRT. A participação dessas empreiteiras potencializou-se, através das parcerias público-privadas (PPP). Esse grupo de UPPs criou condições de segurança e valorização da região portuária alimentando também a especulação imobiliária. A remoção e as expropriações nessa área foram fundamentais. 
O terceiro grupo abrange as UPPs de Nova Brasília, Fazendinha, Adeus e Baiana, Complexo do Alemão, Chatuba, Fé e Sereno, Parque Proletário, Vila Cruzeiro, Lins e Camarista e Méier; a presença da polícia militar nesta região é central para a estratégia de controle, contenção e administração da pobreza. Trata-se de uma área geográfica que concentram os setores mais pauperizados da população residente na cidade e com maior dificuldade de acesso aos serviços básicos (saneamento, água, saúde, educação, transporte etc.

O quarto grupo reúne as primeiras UPPs implantadas na cidade, dentre elas Santa Marta, Babilônia e Chapéu Mangueira, Pavão-Pavãozinho e Cantagalo, Tabajaras e Cabritos, Escondidinho e Prazeres, Vidigal, Rocinha e Cerro Corá, localizadas na zona sul da cidade. Esta região constitui um verdadeiro cinturão turístico-hoteleiro que concentra serviços como hotéis, bares, restaurantes etc. e belezas naturais cobiçadas pelos turistas (praias, parques, lagoas etc.) que contribuem para a valorização dos imóveis e dos terrenos situados nesta região alimentando ao mesmo tempo a especulação imobiliária e os negócios vinculados ao turismo.

O último grupo identificado congrega as UPPs de Borel, Formiga, Andaraí, Salgueiro, Turano, São João, Matriz e Quieto, Macacos, Mangueira e Cidade de Deus, implantadas nas áreas de realização dos grandes eventos esportivos; estas UPPs são fundamentais para efetivar as atividades e obras vinculadas aos megaeventos, garantindo as mudanças urbanas necessárias para o desenvolvimento dos eventos esportivos, assim como a segurança nos estádios, vilas olímpicas e do entorno.

\section{MAPA 1: LOCALIZAÇÃO DAS UPPs (Fonte: Elaboração própria)}

Embora o Decreto 42.787, de 2011, explicite que o Programa das UPPs tem como objetivo "consolidar o controle estatal sobre comunidades sob forte influência da criminalidade ostensivamente armada" buscando garantir a "segurança, cidadania e inclusão social", nossa pesquisa indica, por um lado, que a distribuição das UPPs não se relaciona de forma direta com os índices de violência registrados no Rio de Janeiro, uma vez que essas Unidades concentram-se nas zonas sul, centro e norte da cidade, que segundo dados do Instituto de Segurança Pública (ISP-RJ), não seriam as localidades mais violentas do Rio de Janeiro. Por outro lado, a região oeste que apresenta altos índices de violência e que concentra grande parte das favelas cariocas, possui um quantitativo de UPP muito inferior, assim como uma escassa presença de equipamentos e serviços públicos para atender a demanda da população.

Também é importante mencionar que, nas regiões onde existe uma menor presença das UPPs, registra-se uma maior atuação de grupos das milícias, compostos, principalmente, por policiais civis, militares e bombeiros militares, que desenvolvem a função de garantir a segurança dos moradores. Essa distribuição encontra-se registrada nos dados apresentados pela pesquisa desenvolvida por Zaluar,

fica claro que a expansão das "milícias" pela cidade, se detém em algumas áreas mais próximas à Avenida Brasil, ao aeroporto internacional e ao Porto do Rio de Janeiro, que continuam sob o controle militar de traficantes. (...) [Também a pesquisa indica que] deve-se notar que a origem dos milicianos nos próprios quadros policiais contribui para o estabelecimento da ordem no local. Sendo composta em sua maioria de policiais civis, militares e bombeiros militares, além 
de guardas penitenciários, ativos ou aposentados, a presença desses grupos paraestatais em favelas garante uma presença diferenciada dos agentes públicos de segurança quando raramente aparecem: as incursões policiais são pacíficas quando raramente ocorrem. Enquanto os traficantes sofrem os efeitos de confrontos armados constantes com as polícias, os milicianos contam com a indiferença dos chefes das corporações, que só os atacam quando há ordens superiores. (2012, online)

Dessa forma, parece existir uma divisão do território que concentra as populações mais empobrecidas do Rio de Janeiro entre o domínio das "milícias" e o domínio do tráfico, hoje tensionado pela atuação da polícia militar utilizando as UPPs como uma das suas estratégias.

\section{MAPA 2: VIOLÊNCIA/MILICIAS (Elaboração Própria)}

Um segundo elemento que queríamos destacar diz respeito às estratégias utilizadas por este programa de segurança pública para a "promoção da paz" nas favelas. Entendemos que o Programa das UPPs representou uma mudança significativa na forma de controlar esses territórios através da militarização da vida e do cotidiano dos moradores desses locais, criando verdadeiras brechas entre essas práticas coercitivas e punitivas, e os objetivos declarados no programa: garantia de direitos de cidadania e atendimento das necessidades sociais da população.

Tampouco foi atingida a meta proposta pelos Programas de integrar a favela à dinâmica da cidade através da "pacificação" e posterior "entrada do Estado" pela via do alargamento dos serviços públicos (coleta de lixo, saneamento básico, transporte etc.) e ampliação dos serviços privados (regularização da conexão de energia elétrica e TV a cabo, distribuição de gás etc.) (FGV, 2012). Em alguns casos, quando esse conjunto de serviços privados e/ ou públicos foi ampliado, após a implantação das UPPs; mais do que melhoria na qualidade de vida da população desses bairros, percebe-se um movimento no sentido contrário que diz respeito à expulsão dos moradores dessas comunidades devido à elevação do custo de vida e à especulação imobiliária.

Dessa forma, afirmamos que o Programa de Política Pacificadora que está sendo implantado no Rio de Janeiro, mais do que uma estratégia que contribua para garantir a segurança da população através da viabilização de serviços e proteção dos direitos humanos, se constitui em uma importante estratégia de administração e controle das populações mais empobrecidas, condição essencial para atender as necessidades da acumulação do grande capital especulativo.

Nesse contexto de reorganização do capital sob comando do capital especulativo, a organização dos megaeventos esportivos se coloca como uma oportunidade e alavanca para consolidar novos nichos de valorização e acumulação. Nesse contexto, reduzir os índices de violência através de estratégias de punição e coerção seletivas organizadas pelas UPPs, sob comando da polícia militar, é central para construir uma imagem do Rio de Janeiro como cidade preocupada com as populações empobrecidas e para criar um clima de negócios como forma de atrair os investidores (as empreiteiras, construtoras, empresas imobiliárias), ${ }^{6}$ evidenciando-se assim a íntima relação entre o modelo de segurança pública militarizada (UPP) e a segurança para os negócios. 


\section{CONSIDERAÇÕES FINAIS}

Entendendo a produção do espaço urbano como um processo histórico, podemos analisar o significado das mudanças acontecidas na cidade do Rio de Janeiro para os diferentes sujeitos envolvidos. A partir da pesquisa sobre a implantação do Programa das UPPs, identificamos uma tendência ao atendimento dos interesses do capital (através da criação de novos nichos de valorização) em detrimento das necessidades da maioria trabalhadora (vítimas das remoções, da falta de investimentos em obras de interesse social, por exemplo).

Estas ações na área de segurança pública justificadas na "cultura do medo" são fundamentais para alimentar a indústria bélica, as empresas de seguros e de vigilância privadas, que se transformam, também, em espaços essenciais para a valorização do capital, seja como nicho de investimento do excedente seja como estratégia de controle e administração da superpopulação relativa (requisito fundamental para criar um clima de negócios favoráveis e necessários aos investidores e especuladores).

Dentre as mudanças acontecidas na cidade a partir de 2009, tivemos aqui a preocupação de entender a importância que adquirem as ocupações militarizadas, arbitrárias e violentas desses territórios, com o objetivo declarado de restabelecer a ordem, a legalidade e garantir a segurança pública. Entretanto, tal como foi trabalhado aqui, elas não podem ser desvinculadas das formas de intervenção do Estado para criar as condições necessárias para o capital. Lembrando também que, em muitos casos, essas práticas coercitivas e repressivas viabilizadas pelo poder público são executadas de forma articulada com secretarias responsáveis pela proteção social (como saúde, habitação e assistência).

Embora após a implantação das UPPs, tenham sido desenvolvidos alguns programas socioeducativos destinados a crianças e jovens, na maioria das vezes, estes são desenvolvidos sob a responsabilidade e/ou supervisão da Polícia Militar. Essas atividades mais do que atender as necessidades de lazer da população reproduzem a disciplina e as regras da corporação policial.

Para finalizar, entendemos ser importante destacar que essa realidade sumariada acima não pode ser compreendida como uma consequência da realização dos megaeventos, pelo contrário, estes eventos são mais uma estratégia utilizada para adequar o espaço urbano às condições e necessidades do processo de valorização e acumulação do capital.

\section{NOTAS}

1. Ver: "Mapa da Violência 2012 - Os novos padrões da Violência Homicida no Brasil". Disponível em: <http:/mapadaviolencia.org.br/index.php> Acesso em: set. 2017.

2. O PRONASCI instituído pela Lei n 11.530 (24 de outubro de 2007), vincula-se ao Ministério da Justiça.

3. Para uma reflexão mais aprofundada acerca da crítica a Doutrina de Segurança Nacional consultar Netto (2014).

4. As denúncias da presença dessas práticas e ações foram sendo identificadas e acompanhadas através da nossa pesquisa documental e hemerográfica na qual sistematizamos um conjunto de situações 
vividas pelos moradores e pelos movimentos sociais. Essas práticas e ações indicam a militarização do cotidiano da população. Também é importante mencionar outro mecanismo de denúncia conhecido é a "Cartilha Popular da Santa Marta", elaborada por movimentos sociais dessa favela buscando orientar os moradores sobre seus direitos constitucionais e acerca das obrigações dos policiais militares nas abordagens na favela.

5. Em 21 de janeiro de 2009, o ex-governador Sérgio Cabral Filho institui através do decreto $n^{\circ} 41.650$, a criação do Programa das UPP no Estado do Rio de Janeiro. E só em 2011 aprova-se o decreto que regulamenta a implantação, estrutura, atuação e funcionamento das Unidades de Polícia Pacificadoras.

6. Esses grupos de investidores encontram no Brasil, tal como acharam em outros países que sediaram esses eventos em oportunidades anteriores, atraentes condições e facilidades para realizar seus negócios: pouca fiscalização do Estado, incentivos tributários, pouca mobilização social, facilidade de acessar o fundo público, adequação das normatizações e leis às exigências dos organizadores etc.

\section{REFERÊNCIAS}

ANDERSONS, Perry. Balanço do neoliberalismo. In: SADER, E; GENTILI, P. (org.) Pós-neoliberalismo: as políticas sociais e o Estado democrático. Rio de Janeiro: Paz e Terra, 1995.

ANTUNES, Ricardo. Dimensões da Precarização estrutural do trabalho. In: A perda da razão social do trabalho: terceirização e precarização. São Paulo: Boitempo, 2007.

BRASIL. Governo do Estado do Rio de Janeiro. Decreto no. 41.650 de 21 de Janeiro de 2009. Dispõe sobre a criação da Unidade de Polícia pacificadora e dá outras providências.

BRASIL. Governo do Estado do Rio de Janeiro. Decreto $n^{\circ} .42 .787$ de 6 de Janeiro de 2011. Dispõe sobre a implantação, estrutura, atuação e funcionamento das Unidades de Polícia Pacificadora (UPP) no estado do Rio de Janeiro e dá outras providências. Disponível em: $<$ http://docslide.com.br/documents/ decreto-no-42787-de-06-de-janeiro-de-2011.html>. Acesso em: 22 fev. 2016.

BRASIL. Lei $\mathrm{n}^{\circ}$ 11.530, de 24 de outubro de 2007. Institui o Programa Nacional de Segurança Pública com Cidadania e dá outras providências. Disponível em: < $<$ ttp://www2.camara.leg.br/legin/fed/lei/2007/le i1153024outubro2007561601normaatualizada-pl.html>. Acesso em: 05 ago. 2014

BURGOS, Marcelo Baumann. Dos parques proletários ao Favela-Bairro: as políticas públicas nas favelas do Rio de Janeiro. In: ALVITO, Marcos; ZALUAR, Alba (org.). Um século de Favela. 3.ed. Rio de Janeiro: Editora FGV, 2003. p. 43.

COUTINHO, Ronaldo. A "crise urbana": urbanização da pobreza e a lógica do Capital. 2013. Disponível em: <http://editora.expressãopopular.com.br/batalha-das-ideias>. Acesso em: 5 de abr. 2013.

DAVIS, Michel. Planeta Favela. São Paulo: Boitempo, 2006

FREIRE, M. D. Paradigmas de segurança no Brasil: da Ditadura aos nossos dias. Revista Aurora, São Paulo, ano I, v. 5, p. 49-58, dez. 2009.

FUNDAÇÃO GETÚLIO VARGAS (FGV). Indicadores socioeconômicos nas UPP do Estado do Rio de Janeiro/2012 - N.17. Disponível em: <http://fgvprojetos.fgv.br/sites/fgvprojetos.fgv.br/files/estudo 25. pdf> Acesso em: 29 fev. 2016. 
HARVEY, David. O novo imperialismo. São Paulo: Loyola, 2004.

MARX, Karl. O Capital. Vol. 2. $3^{a}$ edição, São Paulo: Nova Cultural, 1982.

MORÁS, Luis. E. Los dilemas y desafíos de las políticas progresistas de seguridad. Revista Encuentros

Uruguayos, Montevidéu, n. 3, p.6-21, set. 2010.

NETTO, José. P. Capitalismo monopolista e Serviço Social. São Paulo: Cortez, 1996.

SALLA, Fernando. Os impasses da democracia brasileira: o balanço de uma década de políticas para as prisões no Brasil. Revista Lusotopie, Paris, v. 10, p. 420, 2003.

WAISELFISZ, Julio Jacobo. Mapa da Violência 2012: Os novos padrões da Violência Homicida no Brasil. SÃo Paulo: Instituto Sangari, 2011. 245 p. Disponível em: <http:/mapadaviolencia.org.br/index. php>. Acesso em: set. 2017.

ZALUAR, Alba. Juventude violenta: processos, retrocessos e novos percursos. Revista Dados, Rio de Janeiro, v. 55, n. 2, p.s/d, 2012.

MAPA 1: LOCALIZAÇÃO DAS UPPS

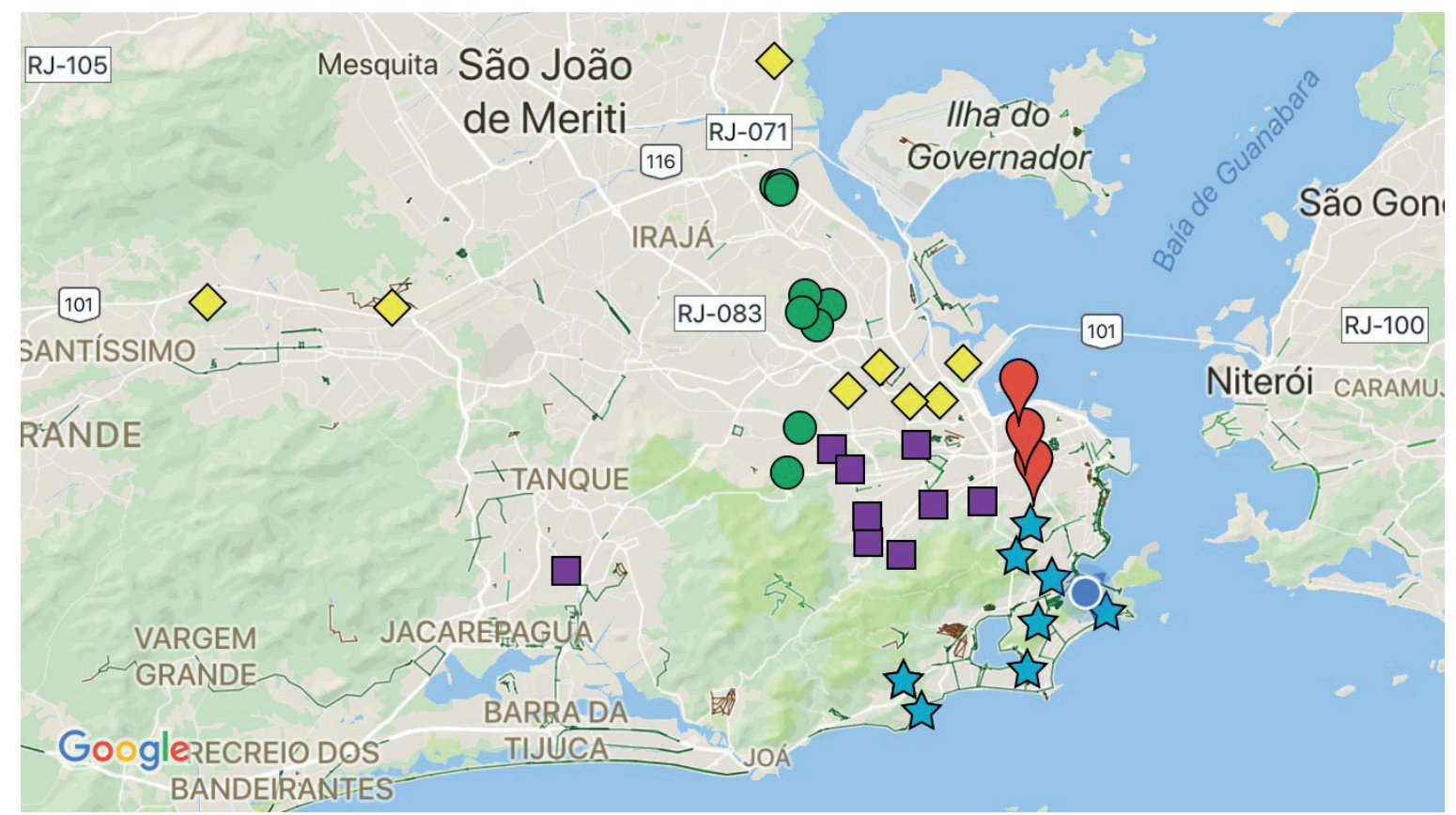

Fonte: Elaboração própria. 
PASTORINI, Alejandra; PERDIGÃO, Ana Carolina; SILVA, Aparecida Tavares da; LIMA, Sara Izabeliza Moreira - Segurança para quem? Unidade de Polícia Pacificadora e gestão da pobreza

\section{MAPA 2: VIOLÊNCIA/MILICIAS}

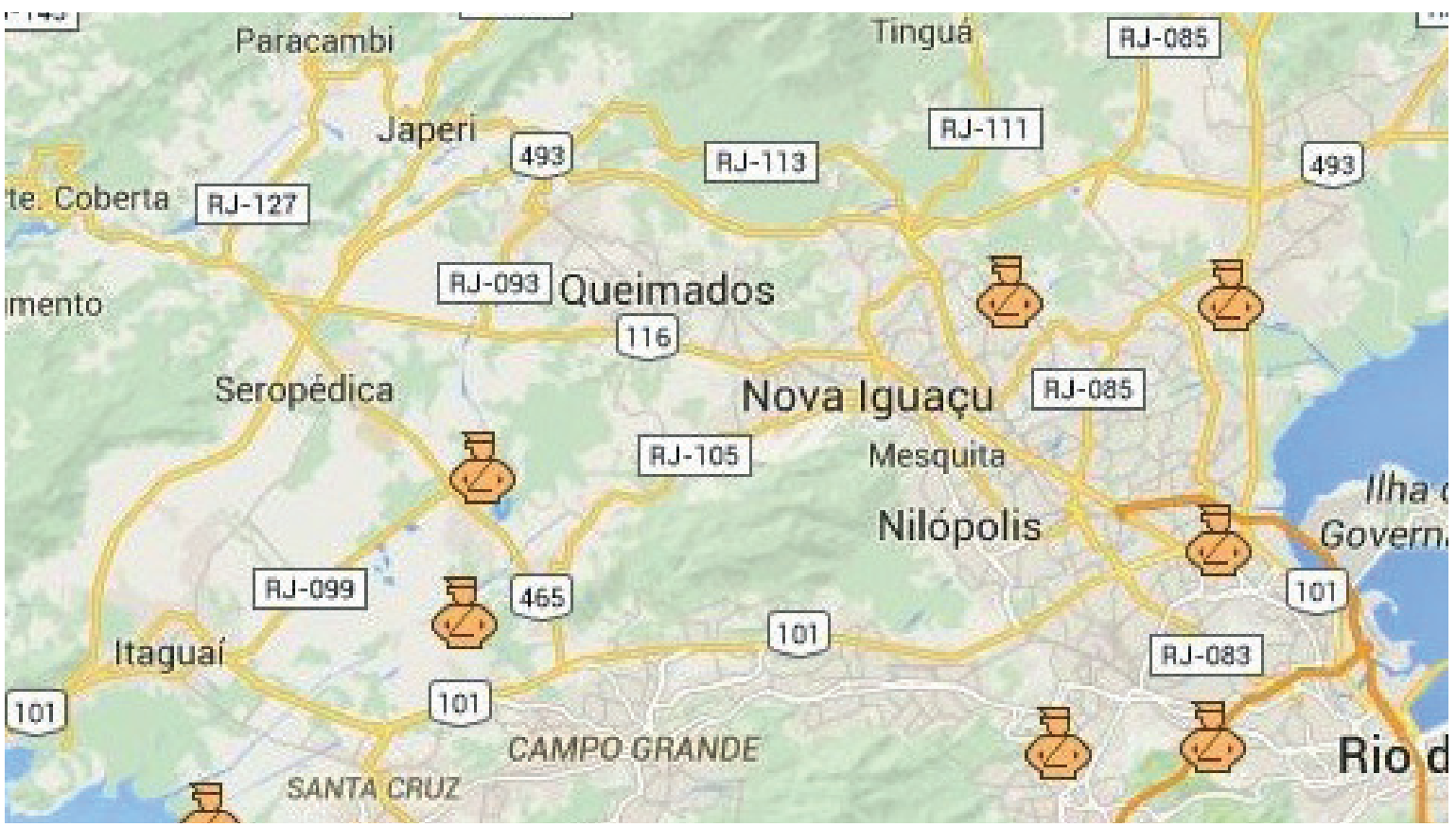

Fonte: Elaboração própria. 